\title{
PRODUTIVIDADE E RESPOSTA DE GENÓTIPOS DE TRIGO AO NITROGÊNIO $\left({ }^{1}\right)$
}

\author{
JOSÉ GUILHERME DE FREITAS $\left({ }^{2,4}\right)$, CARLOS EDUARDO \\ DE OLIVEIRA CAMARGO $\left({ }^{2,4}\right)$, ANTONIO WILSON PENTEADO FERREIRA FILHO $\left({ }^{2,4}\right)$ \\ e ARMANDO PETTINELLI JUNIOR $\left(^{3}\right)$
}

\begin{abstract}
RESUMO
O estudo baseou-se na hipótese de variabilidade genética entre genótipos de trigo (Triticum aestivum L.), a qual permitiria discriminá-los quanto à eficiência na produção de grãos e resposta na utilização do nitrogênio. Os ensaios foram realizados em 1987-91, no Centro Experimental de Campinas e na Estação Experimental de Tatuí, em condiçōes de irrigação por aspersão. Em Campinas, em sucessão ao pousio e, em Tatuí, ao arroz e ao lablabe, em 1987-91. O delineamento estatístico empregado foi de blocos ao acaso, no esquema de parcelas subdivididas, com quatro repetições. A parcela constituiu-se de três doses de nitrogênio $(0,60$ e $120 \mathrm{~kg} / \mathrm{ha})$ e, as subparcelas, dos genótipos de trigo BH-1146, IAC-5, IAC-24, IAC-25, IAC-60, IAC-161, IAC-162 e Anahuac. Os genótipos de trigo IAC-60, IAC-161 e IAC-162 responderam para produção de grãos à aplicação das doses de 60 e $120 \mathrm{~kg} / \mathrm{ha}$ de $\mathrm{N}$ e o restante, somente até $60 \mathrm{~kg} / \mathrm{ha}$ de $\mathrm{N}$ em 1991, no Centro Experimental de Campinas. O genótipo IAC- 60 foi considerado mais produtivo na utilização do nitrogênio aplicado e do existente no solo, para a mesma característica. Na Estação Experimental de Tatuí, após a cultura de arroz (1987), todos os cultivares estudados responderam até $120 \mathrm{~kg} / \mathrm{ha}$ de $\mathrm{N}$, havendo correlação positiva e significativa entre as doses de nitrogênio e a produção de grãos, independente dos genótipos. Nas mesmas condiçōes, após a cultura do lablabe, os genótipos estudados de trigo não responderam à aplicação das doses de nitrogênio, durante os anos de 1988-90.
\end{abstract}

Termos de indexação: nitrogênio, trigo, Triticum aestivum $\mathrm{L}_{\text {, }}$ resposta e produtividade de grãos.

( ${ }^{1}$ Trabalho apresentado na XX Reunião Brasileira de Fertilidade do Solo e Nutrição de Plantas. Piracicaba (SP), 26 a 31 de julho de 1992. Recebido para publicação em 19 de janeiro e aceito em 18 de outubro de 1994.

$\left({ }^{2}\right)$ Seção de Arroz e Cereais de Inverno - Instituto Agronômico de Campinas (IAC), Caixa Postal 28, 13001-970 Campinas (SP).

$\left(^{3}\right)$ Estação Experimental de Tatuí, IAC, Caixa Postal 33. 18270-000 Tatuí (SP).

( ${ }^{4}$ Com bolsa de pesquisa do CNPq. 


\begin{abstract}
RESPONSE AND PRODUCTIVITY OF WHEAT GENOTYPES TO THE NITROGEN

This study was based on the hypothesis of existance of genetic variability among genotypes of wheat (Triticum aestivum L.) in relation to the nitrogen utilization and response to application of this nutrient. The experiments were carried out at the Campinas and Tatuí Experiment Stations, Instituto Agronômico, State of São Paulo, Brazil, under sprinkler irrigation conditions, in succession to fallow (Campinas) and rice or lablab crops (Tatuí), during 1987-1991 years. It was used a randomized complete block design in a split plot arrangement with four replications. The main plots were the levels of nitrogen $(0,60$ and $120 \mathrm{~kg} / \mathrm{ha})$ and the split-plots were the wheat genotypes: BH-1146, IAC-5, IAC-24, IAC-25, IAC-60, IAC-161, IAC-162 and Anahuac. The results showed that in relation to the grain yield, the most productive genotypes were IAC-60, IAC-161 and IAC- 162 which responded up to $120 \mathrm{~kg} / \mathrm{ha}$ of applied nitrogen and the remaining responded only to $60 \mathrm{~kg} / \mathrm{ha}$ of $\mathrm{N}$, in Campinas during 1991. At the Tatuí Experiment Station, in 1987, the most productive genotypes were IAC-60 and IAC-24 and all genotypes responded up to $120 \mathrm{~kg} / \mathrm{ha}$ of applied nitrogen; but they did not respond to the high levels of applied nitrogen, during the years 1988 to 1990 , in succession to lablab crops.
\end{abstract}

Index terms: nitrogen, wheat, Triticum aestivum L., response and efficiency.

\section{INTRODUÇÃO}

Gerloff (1976), estudando a adaptação de plantas a solos com deficiência mineral, mostrou as vantagens das maiores produções e estocagens de alimentos, mediante emprego de genótipos melhorados. Atualmente, alguns programas de melhoramento de plantas levam em consideração que um genótipo ineficiente ou pouco produtivo, sob certa dose crítica de nitrogênio, deveria produzir tanto quanto o eficiente ou mais produtivo nas condições de não-deficiência de tal nutriente. Esse tem sido um ponto para evitar que seja classificado como ineficiente, ao nutriente estudado, um genótipo com outras deficiências fisiológicas, tais como: suscetibilidade ao acamamento, a doenças, à toxicidade de $\mathrm{Al}^{3+}$ (Gerloff, 1976).

Considerou ainda o autor que não é só melhorar a planta que resolve o problema de estresse de nutrientes, mas também controlar o meio, em virtude de os fatores ambientais estarem agindo sobre a planta. Produzir trigo em áreas do mundo onde há necessidade da manipulação do nível de fertilidade, tem sido considerado difícil. Há, portanto, duas opções: a primeira seria o suplemento de nutrientes através de adubação e a outra, selecionar linhagens de plantas eficientes à absorção e utilização de nutrientes (Gerloff, 1976).

O objeto principal da adubação nitrogenada é completar as exigências adequadas de nitrogênio pelas culturas não supridas pelo nitrogênio inorgânico do solo ou pela fixação biológica do nitrogênio atmosférico.

Em anos chuvosos, como 1971, em condições de irrigação, ocorreram altas respostas ao adubo nitrogenado, revelando a influência da disponibilidade de água no aumento da produção de grãos de trigo (Camargo, 1976, e Parameswaran et al., 1984). Outros experimentos, instalados em condições de sequeiro (Camargo \& Alves, 1972; Camargo et al., 1975) com N, P, K e S, indicaram que a dose de $30 \mathrm{~kg} / \mathrm{ha}$ de nitrogênio proporcionou a resposta mais econômica. Para essa mesma condição e após a cultura da soja, não foi recomendada a adubação nitrogenada. Nas condições de irrigação e após pousio, Camargo et al. (1990), fizeram a recomendação de $20 \mathrm{~kg} / \mathrm{ha}$ de $\mathrm{N}$ na semeadura e $40 \mathrm{~kg} / \mathrm{ha}$ em cobertura. A disponibilidade de água 
é muito importante, pois o nitrogênio é absorvido através do fluxo de massa (Epstein, 1975).

Os objetivos deste trabalho foram: (1) estudar as respostas da produção de grãos e outras características agronômicas de diferentes cultivares de trigo a três doses de adubação nitrogenada; (2) avaliar os genótipos mais eficientes na possível utilização do nitrogênio nessas doses, e (3) estudar as correlações entre as doses de nitrogênio e as características agronômicas para cada genótipo.

\section{MATERIAL E MÉTODOS}

Foi instalado, em cada ano, em 1987-91, um ensaio de doses de nitrogênio vérsus genótipos de trigo, no Centro Experimental de Campinas e na Estação Experimental de Tatuí, Instituto Agronômico, latitude $22^{\circ} 53^{\prime}$ e $22^{\circ} 21^{\prime} \mathrm{S}$, longitude $47^{\circ} 03^{\prime}$ 'e $47^{\circ} 51^{\prime} \mathrm{W}$ e altitudes de 663 e 609 metros (Brasil, 1957), respectivamente, em latossolos roxo e vermelho-escuro distróficos, de baixa fertilidade e ácidos, em condições de irrigação. Todos os ensaios semeados em Campinas foram desenvolvidos após pousio, e aqueles semeados em Tatuí, após arroz (1987) e lablabe (1988-91). Os locais estudados encontram-se nas zonas tritícolas H e D respectivamente (Camargo et al., 1990). A irrigação foi de cerca de $30 \mathrm{~mm}$ de água na semeadura e, a cada dez dias, aplicaram-se $20 \mathrm{~mm}$ de água.
O delineamento estatístico utilizado foi de blocos ao acaso, no esquema de parcelas subdivididas com quatro repetições. As parcelas $(1,4 \times 32$ $\mathrm{m}=44,8 \mathrm{~m}^{2}$ foram constituídas por três doses de nitrogênio $(0,60$ e $120 \mathrm{~kg} / \mathrm{ha})$ fornecido como sulfato de amônio (Camargo et al., 1988, 1992).

O nitrogênio foi aplicado $1 / 3$ no sulco de semeadura e $2 / 3$ aos quarenta dias após a emergência das plântulas (Camargo et al., 1988).

Foi feito o acompanhamento da fertilidade do solo, nos dois locais, conforme quadros 1 e 2 .

As subparcelas $\left(1,4 \times 3 \mathrm{~m}=4,2 \mathrm{~m}^{2}\right)$ foram constituídas por oito genótipos de trigo, a saber: BH-1146, IAC-5, IAC-24, IAC-25, IAC-60, IAC-161, IAC-162 e Anahuac.

A densidade de semeadura foi de 80 sementes viáveis por metro linear. Cada subparcela foi formada de sete linhas, espaçadas $0,20 \mathrm{~m}$ uma da outra, sendo as cinco linhas centrais colhidas para quantificar a produtividade.

Coletaram-se, ao acaso, vinte colmos, incluindo as espigas de cada subparcela, no início do espigamento, para análise do teor de nitrogênio na parte aérea, e dez espigas das linhas da bordadura de cada subparcela, visando avaliar as seguintes características agronômicas: comprimento da espiga, número de espiguetas por espiga, número de grãos

Quadro 1. Análises dos solos $\left(^{1}\right)$, na profundidade de $0-20 \mathrm{~cm}$, dos ensaios instalados no Centro Experimental de Campinas em 1987, 1988, 1989 e 1991

\begin{tabular}{lcccc} 
Resultados analíticos & 1987 & 1988 & 1989 & 1991 \\
\hline $\mathrm{P}(\mathrm{mg} / \mathrm{kg})$ & 32 & 27 & 40 & 23 \\
$\mathrm{M} .0 .(\mathrm{g} / \mathrm{kg})$ & 35 & 28 & $\ldots$ & 32 \\
$\mathrm{pH}(\mathrm{CaCl})$ & 4,4 & 4,5 & 4,8 & 5,3 \\
$\mathrm{~K}(\mathrm{cmol} / \mathrm{kg})$ & 3,0 & 3,0 & 2,5 & 3,3 \\
$\mathrm{Ca}(\mathrm{cmol} / \mathrm{kg})$ & 15 & 15 & 17 & 31 \\
$\mathrm{Mg}(\mathrm{cmol} / \mathrm{kg})$ & 7 & 42 & 9 & 12 \\
$\mathrm{H}+\mathrm{Al}(\mathrm{cmol} / \mathrm{kg})$ & 58 & 26 & 38 & 38 \\
$\mathrm{~S}(\mathrm{cmol} / \mathrm{kg})$ & 25 & 68 & 29 & 46 \\
$\mathrm{~T}(\mathrm{cmol} / \mathrm{kg})$ & 83 & 38 & 67 & 84 \\
$\mathrm{~V} \%$ & 30 & 43 & 55 \\
\hline
\end{tabular}

(1) Efetuadas na Seção de Fertilidade do Solo e Nutrição de Plantas, segundo Raij \& Quaggio (1983). 
por espiga e por espigueta e massa de cem grãos (Camargo et al., 1990). Avaliaram-se ainda a altura das plantas e o acamamento, conforme Camargo et al. (1990).

Foram feitas análises individuais da variância para produção de grãos nos nove experimentos e para as características agronômicas, somente para 1988 em Campinas. A análise conjunta da variância foi realizada para produção de grãos, no período de 1987-91, para Campinas, e 1988-90 para Tatuí (Zonta et al., 1987).

Determinaram-se as correlações entre doses de nitrogênio e produção de grãos e características agronômicas, com o objetivo de verificar as associações que foram significativas ao nível de $5 \%$ pelo teste t, para as condiçōes dos ensaios considerados.

\section{RESULTADOS E DISCUSSÃO}

As produções médias de grãos dos genótipos de trigo avaliados, em diferentes doses de nitrogênio nos ensaios do Centro Experimental de Campinas, em 1987-91, encontram-se no quadro 3. Os resultados das análises inviduais da variância desses experimentos mostraram efeitos significativos para dose de nitrogênio, com exceção de 1988 , e para genótipos, com exceção de 1987 , e efeitos não signi- ficativos para interação entre as doses de nitrogênio e genótipos, com exceção de 1991 .

No ensaio de 1991, os genótipos BH-1146, IAC-5, IAC-24, IAC-25 e Anahuac responderam até $60 \mathrm{~kg} / \mathrm{ha}$ de N e IAC-161, IAC-60 e IAC-162 responderam até $120 \mathrm{~kg} / \mathrm{ha}$ de $\mathrm{N}$. Essas variações mostram que, para cada cultivar, é necessária determinada quantidade de adubo nitrogenado (Quadro 3 ).

Os resultados referentes a 1991 (Quadro 3) também mostraram que, na dose zero de $\mathrm{N}$, o genótipo mais produtivo foi o IAC-60. Os cultivares IAC-25, IAC-161 e Anahuac foram considerados também produtivos, por apresentarem as médias das produções de grãos superiores à média geral na dose zero de $\mathrm{N}$ e diferirem dos demais significativamente da média geral nessa dose. O IAC-5 foi medianamente produtivo e os genótipos IAC-24, IAC-162 e BH-1146, menos produtivos na dose zero de nitrogênio, por apresentarem as médias inferiores à geral e diferirem dos demais.

Considerando a dose de $60 \mathrm{~kg} / \mathrm{ha}$ de $\mathrm{N}$, os genótipos mais produtivos ao uso de nitrogênio foram IAC-60, IAC-25, IAC-161 e Anahuac (Quadro 3), sendo menos produtivos os demais com relação à produção de grãos.

Quadro 2. Análises dos solos $\left({ }^{1}\right)$, na profundidade de $0-20 \mathrm{~cm}$ dos ensaios instalados na Estação Experimental de Tatuí nos anos de 1987, 1988, 1989 e 1990

\begin{tabular}{lcccc} 
Resultados analíticos & 1987 & 1988 & 1989 & 1990 \\
\hline $\mathrm{P}(\mathrm{mg} / \mathrm{kg})$ & 40 & 51 & 46 & 58 \\
$\mathrm{M.0.}(\mathrm{g} / \mathrm{kg})$ & 26 & 32 & $\ldots$ & 25 \\
$\mathrm{pH}(\mathrm{CaCl})$ & 5,4 & 5,6 & 6,3 & 5,6 \\
$\mathrm{~K}(\mathrm{cmol} / \mathrm{kg})$ & 3,1 & 5,5 & 4,8 & 4,9 \\
$\mathrm{Ca}(\mathrm{cmol} / \mathrm{kg})$ & 38 & 42 & 53 & 45 \\
$\mathrm{Mg}(\mathrm{cmol} / \mathrm{kg})$ & 17 & 17 & 32 & 17 \\
$\mathrm{H}+\mathrm{Al}(\mathrm{cmol} / \mathrm{kg})$ & 27 & 24 & 16 & 28 \\
$\mathrm{~S}(\mathrm{cmol} / \mathrm{kg})$ & 58 & 65 & 90 & 67 \\
$\mathrm{~T}(\mathrm{cmol} / \mathrm{kg})$ & 85 & 89 & 106 & 95 \\
$\mathrm{~V} \%$ & 68 & 73 & 85 & 71 \\
\hline
\end{tabular}

( ${ }^{1}$ Efetuadas na Seção de Fertilidade do Solo e Nutriçāo de Plantas, segundo Raij \& Quaggio (1983). 
Quadro 3. Produção de grãos dos genótipos de trigo, em condições de irrigação, do ensaio instalado no Centro Experimental de Campinas, de 1987 a 1991 (médias de quatro repetições)

\begin{tabular}{|c|c|c|c|c|c|c|c|}
\hline Genótipos & Doses de $\mathrm{N}$ & 1987 & 1988 & 1989 & 1990 & $1991\left(^{1}\right)$ & Médias \\
\hline $\mathrm{BH}-1146$ & 0 & 2432 & 3057 & 2754 & 2478 & $2449 \mathrm{e}$ & 2634 \\
\hline IAC-5 & & 2436 & 2781 & 2472 & 1820 & $3083 b c$ & 2518 \\
\hline IAC- 24 & & 2849 & 3351 & 2454 & 2120 & $2646 \mathrm{de}$ & 2684 \\
\hline IAC- 25 & & 2597 & 3331 & 3208 & 2540 & $3342 b$ & 3004 \\
\hline IAC -60 & & 2300 & 2940 & 3132 & 2182 & $3524 a$ & 2816 \\
\hline IAC- 161 & & 2015 & 2528 & 2082 & 3557 & $3291 b$ & 2695 \\
\hline IAC- 162 & & 2413 & 3179 & 2684 & 1838 & $2839 \mathrm{~cd}$ & 2591 \\
\hline Anahuac & & 2478 & 2683 & 3152 & 2497 & $3352 b$ & 2833 \\
\hline Médias & & 2440 & 2981 & 2742 & 2379 & 3071 & $2722 B$ \\
\hline BH-1146 & 60 & 2798 & 2806 & 3080 & 3012 & $2869 \mathrm{c}$ & 2912 \\
\hline IAC-5 & & 2503 & 3136 & 3096 & 3084 & $3351 b$ & 3034 \\
\hline IAC- 24 & & 3010 & 3680 & 3176 & 3413 & $3102 b c$ & 3276 \\
\hline IAC-25 & & 2874 & 3453 & 3144 & 2623 & $4037 a$ & 3226 \\
\hline IAC- 60 & & 2280 & 3183 & 3542 & 4106 & $4043 a$ & 3431 \\
\hline IAC-161 & & 2495 & 3147 & 2316 & 3840 & $3934 a$ & 3146 \\
\hline IAC- 162 & & 2776 & 2821 & 2664 & 2661 & $3314 \mathrm{~b}$ & 2647 \\
\hline Anahuac & & 2787 & 3096 & 3228 & 2772 & $3859 a$ & 3148 \\
\hline Médias & & 2690 & 3165 & 3031 & 3189 & 3564 & $3103 \mathrm{~A}$ \\
\hline $\mathrm{BH}-1146$ & 120 & 2786 & 2861 & 3114 & 2364 & $2719 \mathrm{e}$ & 2769 \\
\hline IAC- 5 & & 2621 & 3235 & 3348 & 2500 & $3359 d$ & 3013 \\
\hline IAC-24 & & 3021 & 3197 & 3600 & 2499 & $3187 d$ & 3101 \\
\hline IAC- -25 & & 3224 & 3197 & 3402 & 2499 & $4093 b$ & 3283 \\
\hline IAC -60 & & 2332 & 3211 & 3696 & 4263 & $4347 a$ & 3570 \\
\hline IAC- 161 & & 3175 & 2712 & 2568 & 3381 & $4372 a$ & 3242 \\
\hline IAC- 162 & & 3395 & 2913 & 3120 & 3381 & $3635 c$ & 3298 \\
\hline Anahuac & & 3522 & 2066 & 3546 & 2472 & $3795 c$ & 2880 \\
\hline Médias & & 3010 & 2924 & 3299 & 2920 & 3688 & $3143 \mathrm{~A}$ \\
\hline FN $\left({ }^{2}\right)$ & & $6,4^{*}$ & $1,7^{\mathrm{ns}}$ & $11,3^{*}$ & $8,2^{*}$ & $25,7^{*}$ & $29,9^{*}$ \\
\hline $\mathrm{FG}\left({ }^{3}\right)$ & & $1,6^{\mathrm{ns}}$ & $4,7^{*}$ & $6,7^{*}$ & $3,7^{*}$ & $35,2^{*}$ & $8,7^{*}$ \\
\hline $\mathrm{FN} \times \mathrm{G}\left({ }^{4}\right)$ & & $0,6^{\mathrm{ns}}$ & $1,3^{\mathrm{ns}}$ & $0,6^{\mathrm{ns}}$ & $1,6^{\mathrm{ns}}$ & $2,6^{*}$ & $2,2^{\mathrm{ns}}$ \\
\hline $\mathrm{CV}(\%)$ & & 24,3 & 17,7 & 12,0 & 11,0 & 7,3 & 18,5 \\
\hline
\end{tabular}

(1) Médias seguidas pela mesma letra, na coluna dentro de cada dose, não diferiram entre si ao nível de $5 \%$, pelo teste de Duncan.

$\left({ }^{2}\right) F$ para as doses de nitrogênio. $\left(^{3}\right) \mathrm{F}$ para os genótipos. $\left({ }^{4}\right) \mathrm{F}$ para a interação entre as doses de nitrogênio e genótipos. 
$\mathrm{Na}$ dose de $120 \mathrm{~kg} / \mathrm{ha}$, os genótipos mais produtivos foram: IAC-60 e IAC-161; os medianamente produtivos: IAC-25, Anahuac e IAC-162; os menos produtivos, os demais, por apresentarem médias da produção de grãos inferiores à geral (3.688 $\mathrm{kg} / \mathrm{ha}$ ).

Os resultados da análise de variância conjunta da produção de grãos, dos ensaios instalados no Centro Experimental de Campinas, no período 1987-91, apresentaram somente efeitos significativos para as doses de nitrogênio e para genótipos. A interação entre esses dois componentes da análise de variância não foi significativa (Quadro 4). As médias da produção de grãos das doses de nitrogênio, independentes dos genótipos estudados (Quadro 3), mostraram que, com a aplicação de $60 \mathrm{~kg} / \mathrm{ha}$ de $\mathrm{N}$, ocorreu um acréscimo médio de $381 \mathrm{~kg} / \mathrm{ha}$ na produção de grãos; contudo, o aumento na dose de nitrogênio de 60 para 120 $\mathrm{kg} / \mathrm{ha}$ de $\mathrm{N}$, causou um acréscimo de $40 \mathrm{~kg} / \mathrm{ha}$, estando esses resultados de acordo com os obtidos por Camargo \& Felício (1985).

Avaliando as produções de grãos dos genótipos, independentemente das doses de $\mathrm{N}$, no período considerado, verificou-se que os genótipos IAC-25, IAC-60 e IAC-24 foram os mais produtivos (Quadro 4).

As médias dos teores de nitrogênio na parte aérea das plantas de trigo, dos genótipos avaliados, em relação às diferentes doses de nitrogênio, no ensaio instalado no Centro Experimental de Campinas, em 1988, encontram-se no quadro 5.

Os resultados da análise da variância individual mostraram somente efeitos significativos para genótipos e para a interação entre doses de nitrogênio e genótipos. O teor de nitrogênio na parte aérea foi maior para o 'IAC-60' e menor para o 'Anahuac' nas três doses de nitrogênio usadas. Conseqüentemente, o 'IAC-60' apresentou maior eficiência de absorção de $\mathrm{N}$ em relação ao 'Anahuac'.

Nas médias de altura das plantas - Quadro 5 os resultados da análise da variância mostraram efeitos significativos somente para genótipos. Os cultivares IAC-5 e BH-1146 apresentaram a maior altura de planta e o maior índice de acamamento.
Com o aumento das doses de nitrogênio, houve um acréscimo na altura das plantas e do acamamento, fato esse prejudicial para a realização da colheita mecânica. As demais variedades, com porte médio e baixo, não mostraram a ocorrência de acamamento.

As características agronômicas número de espiguetas por espiga e de grãos por espigueta, para as diferentes doses de nitrogênio, no ensaio do Centro Experimental de Campinas, em 1988, encontram-se também no quadro 5. As análises da variância dessas características mostraram efeitos significativos para genótipos e doses de nitrogênio e não significativos para a interação entre eles.

Quadro 4. Produção de grãos dos genótipos de trigo em condições de irrigação, independente das doses de nitrogênio, estudadas nos ensaios do Centro Experimental de Campinas, de 1987 a $1991{ }^{1}{ }^{1}$ ). Médias de repetições e doses de $\mathrm{N}$ )

Genótipos Prođução de grãos

\begin{tabular}{lc} 
& $\mathrm{kg} / \mathrm{h}$ \\
BH-1146 & $2807 \mathrm{c}$ \\
IAC-5 & $2861 \mathrm{c}$ \\
IAC-24 & $3128 \mathrm{ab}$ \\
IAC-25 & $3229 \mathrm{a}$ \\
IAC-60 & $3227 \mathrm{a}$ \\
IAC-161 & $2949 \mathrm{bc}$ \\
IAC-162 & $2879 \mathrm{c}$ \\
Anahuac & $2926 \mathrm{c}$ \\
Média & 3001 \\
FN $\left({ }^{2}\right)$ & $29,9^{*}$ \\
FG $\left({ }^{3}\right)$ & $8,7^{*}$ \\
FN x G $\left({ }^{4}\right)$ & $2,2^{\mathrm{ns}}$ \\
CV $(\%)$ & 18,5 \\
\hline
\end{tabular}

(') Médias seguidas pela mesma Ietra, na coluna, independente da dose de nitrogênio, não diferiram entre si ao nível de $5 \%$, pelo teste de Duncan. $\left({ }^{2}\right) \mathrm{F}$ para as doses de nitrogênio. ( $\left.{ }^{3}\right) \mathrm{F}$ para os genótipos. $\left(^{4}\right) \mathrm{F}$ para a interação entre as doses de nitrogênio e genótipos. 
Quadro 5. Teores de nitrogênio na parte aérea $(\mathrm{N})$, altura da planta (AP), número de espiguetas por espiga (NEE), número de grãos por espigueta (NGE) e por espiga (NGES), massa de cem grãos (MCG), comprimento da espiga (CE) e acamamento 0-100\% (A), dos genótipos de trigo, em três doses de nitrogênio, em condições de irrigação, no ensaio do Centro Experimental de Campinas, em 1988 ( $\left.^{1}\right)$ (médias de quatro repetições)

\begin{tabular}{|c|c|c|c|c|c|c|c|c|c|}
\hline Genótipos & Doses de $\mathrm{N}$ & $\mathrm{N}$ & AP & NEE & NGE & NGES & MCG & $\mathrm{CE}$ & A \\
\hline & $\mathrm{kg} / \mathrm{ha}$ & $\mathrm{g} / \mathrm{kg}$ & $\mathrm{cm}$ & $\mathrm{n}^{\circ}$ & $n^{0}$ & $n^{\circ}$ & $\mathrm{mg}$ & $\mathrm{cm}$ & $0-100 \%$ \\
\hline BH-1146 & 0 & $22 \mathrm{c}$ & 106 & 17 & 2,0 & $32 \mathrm{e}$ & 4,0 & 7,7 & 20 \\
\hline IAC-5 & & $23 b c$ & 113 & 21 & 1,9 & $39 d$ & 4,2 & 9,3 & 20 \\
\hline IAC- 24 & & $23 b c$ & 74 & 18 & 2,5 & $46 a b c$ & 3,6 & 8,9 & 0 \\
\hline IAC- 25 & & $26 a$ & 84 & 19 & 2,4 & $44 b c d$ & 3,9 & 9,7 & 0 \\
\hline IAC- 60 & & $25 \mathrm{ab}$ & 87 & 22 & 2,3 & $54 \mathrm{ab}$ & 3,6 & 10,0 & 0 \\
\hline IAC-161 & & $21 \mathrm{c}$ & 86 & 21 & 2,7 & $55 a$ & 3,9 & 9,2 & 0 \\
\hline IAC- 162 & & $25 \mathrm{ab}$ & 80 & 17 & 2,5 & $43 \mathrm{~cd}$ & 4,2 & 9,1 & 0 \\
\hline Anahuac & & $21 \mathrm{c}$ & 73 & 19 & 2,4 & $38 \mathrm{~d}$ & 4,0 & 8,9 & 0 \\
\hline Médias & & 23 & 88 & 19 & 2,3 & 44 & 3,3 & 9,1 & - \\
\hline BH-1146 & 60 & $25 b$ & 113 & 18 & 1,9 & $32 d$ & 4,4 & 8,0 & 20 \\
\hline IAC-5 & & $24 b c$ & 115 & 21 & 2,0 & $42 b c$ & 4,0 & 9,4 & 20 \\
\hline $\mathrm{IAC}-24$ & & $25 \mathrm{bc}$ & 70 & 19 & 2,4 & $41 b c$ & 3,7 & 8,4 & 0 \\
\hline IAC- 25 & & $24 \mathrm{~b}$ & 80 & 21 & 2,5 & $43 a b c$ & 3,7 & 9,8 & 0 \\
\hline IAC- 60 & & $28 \mathrm{a}$ & 86 & 21 & 2,4 & $49 \mathrm{a}$ & 4,1 & 10,1 & 0 \\
\hline IAC-161 & & $25 b$ & 73 & 21 & 2,4 & $48 \mathrm{ab}$ & 3,8 & 9,2 & 0 \\
\hline IAC- 162 & & $25 b$ & 80 & 19 & 2,5 & $46 a b$ & 4,3 & 9,7 & 0 \\
\hline Anahuac & & $22 \mathrm{c}$ & 73 & 19 & 2,3 & $46 a b$ & 3,7 & 9,4 & 0 \\
\hline Média & & 25 & 86 & 20 & 2,3 & 43 & 4,0 & 9,3 & - \\
\hline $\mathrm{BH}-1146$ & 120 & $21 \mathrm{c}$ & 102 & 18 & 2,1 & $35 \mathrm{~d}$ & 4,1 & 8,2 & 20 \\
\hline IAC-5 & & $25 \mathrm{ab}$ & 117 & 21 & 2,1 & $44 \mathrm{bd}$ & 4,4 & 9,3 & 40 \\
\hline IAC-24 & & $26 a$ & 80 & 19 & 2,3 & $42 \mathrm{bcd}$ & 3,7 & 8,8 & 0 \\
\hline IAC-25 & & $23 b$ & 80 & 18 & 2,5 & $48 b$ & 3,6 & 9,6 & 0 \\
\hline IAC -60 & & $25 a b$ & 88 & 21 & 1,9 & $42 \mathrm{bcd}$ & 4,3 & 10,1 & 0 \\
\hline IAC-161 & & $25 \mathrm{ab}$ & 75 & 21 & 2,6 & $55 a$ & 4,3 & 9,8 & 0 \\
\hline IAC- 162 & & $25 a$ & 75 & 18 & 2,4 & $47 b$ & 4,2 & 9,1 & 0 \\
\hline Anahuac & & $19 \mathrm{c}$ & 65 & 19 & 2,3 & $39 \mathrm{~cd}$ & 2,9 & 9,0 & 0 \\
\hline Médias & & 24 & 85 & 19 & 2,3 & 44 & 3,9 & 9,2 & - \\
\hline FN $\left({ }^{2}\right)$ & & $1,4^{\mathrm{ns}}$ & $0,3^{\mathrm{ns}}$ & $8,7^{*}$ & $3,2^{*}$ & $0,3^{\mathrm{ns}}$ & $0,2^{\mathrm{ns}}$ & $0,8^{\mathrm{ns}}$ & - \\
\hline $\mathrm{FG}\left({ }^{3}\right)$ & & $4,0^{*}$ & $100,6^{*}$ & $19,3^{*}$ & $6,4 *$ & $11,5^{*}$ & $9,2 *$ & $26,9 *$ & - \\
\hline$F N \times G\left({ }^{4}\right)$ & & $1,6^{*}$ & $1,4^{\mathrm{ns}}$ & $0,83^{\mathrm{ns}}$ & $0,8^{\mathrm{ns}}$ & $1,5^{*}$ & $1,3^{\mathrm{ns}}$ & $1,4^{\mathrm{nS}}$ & - \\
\hline $\mathrm{CV}(\%)$ & & 10,1 & 5,7 & 6,9 & 12,1 & 9,8 & 9,2 & 4,51 & - \\
\hline
\end{tabular}

( $\left.{ }^{1}\right)$ Médias seguidas pela mesma letra, na coluna, não diferiram entre si, ao nível de $5 \%$, pelo teste de Duncan. $\left({ }^{2}\right) \mathrm{F}$ para as doses de nitrogênio. ( $\left.{ }^{3}\right) \mathrm{F}$ para os genótipos de trigo. $\left(^{4}\right)$ F para a interação entre as doses de nitrogênio e genótipos. ns - Não significativo. * Significativo ao nível de $5 \%$ pelo teste $\mathrm{F}$. 
geada. As análises individuais e conjunta mostraram efeitos significativos para genótipos e não significativos para a interação entre genótipos e doses de nitrogênio.

O efeito das doses de nitrogênio foi significativo, no ensaio instalado após a cultura do arroz (1987) e não significativo, nos ensaios simulados em sucessão ao lablabe (1988 a 1990, Quadro 6). Esses resultados concordam com os obtidos por Camargo et al. (1985). Após a cultura do arroz, os genótipos de trigo mais produtivos, independentemente da dose de $\mathrm{N}$, foram IAC-60, IAC-161 e IAC-24 e, com menor rendimento, BH-1146, IAC-25, Anahuac e IAC-162. Em sucessão ao lablabe, os genótipos de trigo mais produtivos, nas médias dos três experimentos (1988-90), foram IAC-60, IAC-162, Anahuac, IAC-25 e IAC-24, e os menos produtivos, IAC-5 e BH-1146 (Quadro 6).

A curva de resposta da produção de grãos, após a cultura do arroz, independentemente dos genótipos de trigo, foi linear em função das doses de nitrogênio (Figura 1), mostrando que, para cada quilograma de nitrogênio aplicado por hectare, ocorreu um aumento de $10,2 \mathrm{~kg}$ de grãos de trigo.
Camargo et al. (1990), após a cultura de arroz, obteve resposta à adubação nitrogenada até $120 \mathrm{~kg} / \mathrm{ha}$ de N. Esses resultados evidenciam a importância da cultura antecessora tanto na recomendação da adubação nitrogenada como na seleção e avaliação de genótipos.

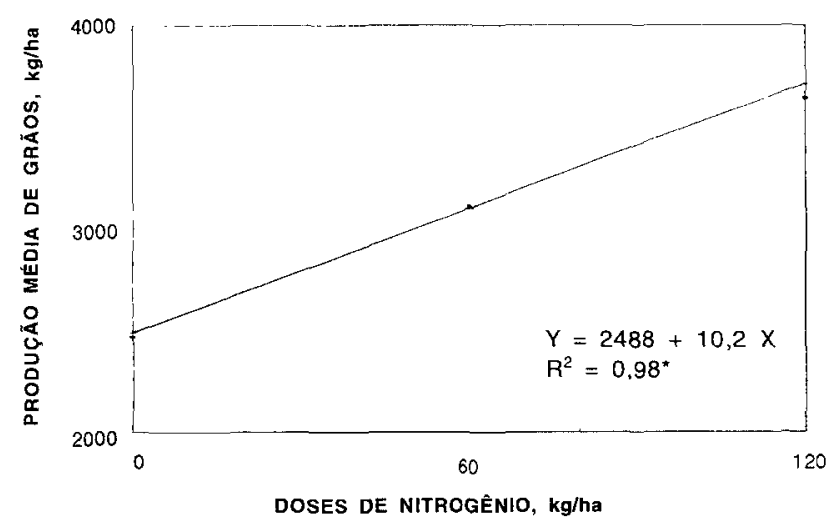

Figura 1. Resposta dos genótipos de trigo, em relação à produção de grãos, a três doses de nitrogênio, em condição de irrigação por aspersão e após a cultura de arroz, na Estação Experimental de Tatú, 1987.

Quadro 7. Correlações entre doses de nitrogênio e características agronômicas dos genótipos de trigo, em condições de irrigação, na Estação Experimental de Tatuí, 1987

Características agronômicas $\left({ }^{1}\right)$

Genótipos

\begin{tabular}{llllll} 
BH-1146 IAC-24 & IAC-25 & IAC-60 & IAC-161 & IAC-162 & Anahuac \\
\hline
\end{tabular}

\begin{tabular}{lccccccc} 
Produção de grāos (kg/ha) & $0,61^{*}$ & $0,61^{*}$ & $0,67^{*}$ & $0,80^{*}$ & $0,90^{*}$ & $0,70^{*}$ & $0,86^{*}$ \\
Comprimento da espiga (cm) & $-0,02$ & $-0,02$ & $0,72^{*}$ & 0,53 & $0,66^{*}$ & 0,24 & $0,86^{*}$ \\
Espiguetas/espiga (n. ${ }^{\circ}$ & $-0,21$ & $-0,22$ & 0,00 & 0,50 & 0,27 & 0,00 & $0,85^{*}$ \\
Grãos/espigueta (n. $\left.{ }^{\circ}\right)$ & $-0,10$ & $-0,17$ & $0,80^{*}$ & $-0,03$ & $0,83^{*}$ & 0,42 & $0,62^{*}$ \\
Grãos/espiga (n. ${ }^{*}$ ) & $-0,20$ & $-0,20$ & $0,88^{*}$ & 0,28 & $0,72^{*}$ & 0,28 & $0,72^{*}$ \\
Peso de cem grãos (mg) & $-0,27$ & $-0,27$ & $-0,33$ & $-0,09$ & 0,42 & $-0,38$ & 0,18 \\
Altura da planta (cm) & 0,00 & 0,00 & 0,16 & 0,51 & 0,18 & $-0,08$ & 0,52 \\
Acamamento (notas 0-5) & 0,18 & 0,18 & 0,10 & 0,37 & - & $-0,55$ & 0,27 \\
Nitrogênio na parte aérea (\%) & 0,04 & 0,04 & 0,11 & 0,08 & 0,10 & 0,17 & 0,16 \\
\hline
\end{tabular}

( ${ }^{1}$ Correlacionadas com doses de nitrogênio. * Significativo ao nível de 5\%, pelo teste t. 
As correlações entre as características agronômicas $e$ as doses de nitrogênio encontram-se no quadro 7. As correlações entre doses de nitrogênio e produção de grãos no ensaio após arroz foram positivas e significativas ao nível de $5 \%$, pelo teste t, para todos os genótipos, destacando-se IAC-161, IAC-60 e Anahuac, com valores entre 0,80 e 0,90 (Quadro 7). Entre as outras características agronômicas, as que mais correlacionaram significativamente com as doses de nitrogênio foram comprimento da espiga, número de grãos por espigueta e por espiga (Quadro 7), para os genótipos de trigo IAC-25, IAC-161 e Anahuac. Os dados sugerem que essas caracteristicas foram as mais influenciadas pela adubação nitrogenada, em condições de irrigação e após a cultura do arroz.

\section{CONCLUSÃO}

Os genótipos de trigo IAC-60, IAC-161 e IAC162 responderam para produção de grãos à aplicação das doses de 60 e $120 \mathrm{~kg} / \mathrm{ha}$, a qual correlacionou com o teor de $\mathrm{N}$ na parte aérea, em 1991, no Centro Experimental de Campinas.

\section{REFERÊNCIAS BIBLIOGRÁFICAS}

BRASIL. Fundação Instituto Brasileiro de Geografia e Estatística. Campinas, Tatuí. In: ENCICLOPÉDIA dos municípios brasileiros. Rio de Janeiro, IBGE, 1957. v.28, 218p.

CAMARGO, C.E.O. Adubação de trigo. IX. Interpretação econômica dos resultados em experimentos com $\mathrm{N}, \mathrm{P}, \mathrm{K}$ e S, em latossolo roxo do Estado de São Paulo. Bragantia, Campinas 35(1): 95-106, 1976.

CAMARGO, C.E.O. \& ALVES, S. Adubação do trigo. III. Experiência com N, P, K e S, em solos de baixada, tipo massapé, de Monte Alegre do Sul, SP. Bragantia, Campinas, 31(28): 337-348, 1972.

CAMARGO, C.E.O. \& FELICIO, J.C. Recomendação de adubação para o trigo. In: RAIJ, B. van; SILVA, N.M.; BATAGLIA, O.C.; QUAGGIO, J.A.; HIROCE, R.; CANTARELLA, H.; BELINAZZI JUNIOR,R.; DECHEN, A.R. \& TRANI, P.E. Recomendações de adubação e calagem para o Estado de São Paulo. Campinas, Instituto Agronômico, 1985. p.26-27. (Boletim técnico, 100)
CAMARGO, C.E.O.; FELÍCIO, J.C.; FERREIRA FILHO, A.W.P.; FREITAS, J.G.; PETTINELLI JUNIOR, A.; RAMOS, V.J. \& KANTHACK, R.A.D. Adubação N, $P, K$ e S para a cultura de trigo no Estado de São Paulo. Campinas, Instituto Agronômico, 1990. 33p. (Boletim técnico, 129)

CAMARGO, C.E.O.; FELÍCIO, J.C.; FERREIRA FILHO, A.W.P.; FREITAS, J.G.; PETTINELLI JUNIOR, A.; RAMOS, V.J. \& KANTHACK, R.A.D. Adubaçăo N, $P, K$ e $S$ para a cultura de trigo em condiçāo de irrigação por aspersão. Campinas, Instituto Agronômico, 1992. 12p. (Boletim técnico, 145)

CAMARGO, C.E.O.; FELÍCIO, J.C.; PETTINELLI JUNIOR, A. \& ROCHA JUNIOR, L.S. Adubação nitrogenada em cultura de trigo irrigado por aspersão no Estado de São Paulo. Campinas, IAC, 1988. 26p. (Boletim científico, 15)

CAMARGO, C.E.O.; VEIGA, A.A.; PESSINI, A.L. \& MONTEIRO, D.A. Adubação do trigo. VII. Experiência com N, P, K e S em diferentes tipos de solos do Estado de São Paulo. Bragantia, Campinas, 34(18): 273-286, 1975.

EPSTEIN, E.A. Aquisição de nitrogênio. In: EPSTEIN, E.A. Nutrição mineral das plantas: princípios e perspectivas. Rio de Janeiro, Livros Técnicos e Científicos; São Paulo, EDUSP, 1975. p. 213-234.

EVANS, L.T.; WARLAN, I.F. \& FISHER, R.A. Wheat. In: EVANS, L.T. Crop phisiology. London, Cambridge University Press, 1975. p. 101-149.

GERLOFF, G.C. Plant efficiences in the use of nitrogen, phosphorus, and potassium. In: WRIGHT, M.J. Plant adaptation to mineral stress in problem soils. Ithaca, Cornell University, 1976. p.161-173.

PARAMESWARAN, K.V.M.; GRAHAM, R.D. \& ASPINALL, D. Studies on the nitrogen and water relations of wheat. II. Effects of varying nitrogen and water supply on growth and grain yield. Irrigation Science, Berlin, 5:105-121, 1984.

RAIJ, B. van \& QUAGGIO, J.A. Métodos de análise de solo para fins de fertilidade. Campinas, IAC, 1983. 31p. (Boletim técnico, 81)

ZONTA, E.P.; MACHADO, A.A. \& SILVEIRA JUNIOR, P. SANEST: sistemas de análise estatística para microcomputadores. Manual de utilização. Pelotas, 1987. $1 \mathrm{v}$. 